\title{
Infusional high-density lipoproteins therapies as a novel strategy for treating atherosclerosis
}

Belinda A. Di Bartolo, Nisha Schwarz, Jordan Andrews, Stephen J. Nicholls

South Australian Health and Medical Research Institute, University of Adelaide, Adelaide, Australia

Submitted: 27 August 2015

Accepted: 18 November 2015

Arch Med Sci 2017; 13, 1: 210-214

DOI: 10.5114/aoms.2016.60941

Copyright @ 2016 Termedia \& Banach

\author{
Corresponding author: \\ Stephen Nicholls \\ South Australian Health \\ and Medical Research \\ Institute \\ PO Box 11060 \\ Adelaide, SA, 5001, Australia \\ Phone: +61-8-8128-4510 \\ E-mail: stephen.nicholls@ \\ sahmri.com
}

\begin{abstract}
High-density lipoproteins (HDL) have received considerable interest as a target for the development of novel anti-atherosclerotic agents beyond conventional approaches to lipid lowering. While a number of approaches have focused on modifying remodeling and expression pathways implicated in the regulation of HDL levels, an additional approach involves simply infusions of delipidated HDL. Several groups have advanced HDL infusions to clinical development with intriguing signs suggesting potentially favorable impacts at the level of the artery wall. The findings of early studies of infusional HDL therapies will be reviewed.
\end{abstract}

Key words: high density lipoprotein, risk factors, lipids, atherosclerosis, clinical trials, imaging.

\section{Introduction}

The unequivocal clinical benefit of lowering levels of low-density lipoprotein cholesterol (LDL-C) with statins has had a profound impact on cardiovascular outcomes in the patient with established coronary artery disease [1-4]. However, despite their widespread use there continues to be a considerable rate of cardiovascular events in the statin-treated patient [5]. This ongoing cardiovascular risk emphasizes the need to develop novel therapeutic strategies that will produce incremental risk reduction. Increasing interest has focused on pharmacological strategies that target the functional properties of high-density lipoproteins ( $\mathrm{HDL})$, the putative protective lipid fraction in plasma.

\section{Evidence supporting a protective role for HDL}

Following the early reports that patients with myocardial infarction had lower levels of HDL-C on ultracentrifugation, a number of lines of evidence have accumulated supporting a potentially protective role of HDL in cardiovascular disease [6, 7]. Population studies consistently demonstrate an inverse relationship between $\mathrm{HDL}-\mathrm{C}$ levels and the prospective risk of cardiovascular events, which continues to be observed regardless of the level of atherogenic lipid factors [8-11]. Animal studies have demonstrated that targeting HDL via direct infusion or transgenic expression of its major proteins results in a favorable effect on both the size and histologic composition of atherosclerotic plaque [12-14]. HDL 
possess a number of functional properties that may contribute to these favorable effects on the artery wall. In addition to their well-characterized roles in promoting cholesterol efflux and reverse cholesterol transport, HDL have also been demonstrated to exert favorable effects on inflammatory, oxidative, apoptotic and thrombotic pathways implicated in atherosclerosis [15]. The degree to which these non-lipid transporting activities are related to the ability of HDL to promote the bioavailability of nitric oxide is uncertain. More recent investigations have focused on the functional quality of HDL, which may differ between various HDL subspecies and in a range of clinical settings such as inflammation, smoking, renal dysfunction and diabetes [16-22]. Accordingly, there is interest not only in raising $\mathrm{HDL}-\mathrm{C}$, but more importantly in promoting functional forms of $\operatorname{HDL}[23,24]$.

\section{Current approaches to targeting HDL}

Existing approaches to management of lipids have modest effects on HDL-C levels [25]. While lifestyle modification is central to all approaches to cardiovascular prevention, the HDL-C raising effect is modest, predominantly occurring in the setting of weight loss. Statins and fibrates both raise HDL-C by up to $20 \%$ at most, with evidence from outcome and imaging trials suggesting that these HDL-C changes independently associate with their benefit [26-29]. While niacin is the most effective HDL-C raising agent currently used in clinical practice, with early evidence of benefit prior to the advent of statins and a favorable influence on disease progression on imaging [30-32], it has failed to demonstrate widespread benefit in the contemporary era of the statin-treated patient.

Cholesteryl ester transfer protein (CETP) inhibition demonstrated potential interest due to its HDL cholesterol raising properties [33]. However, even with substantial increases in HDL cholesterol and LDL cholesterol lowering in statin treated patients, torcetrapib (the first potent CETP inhibitor) resulted in adverse cardiovascular effects [34-36]. Since then the development of another CETP inhibitor (dalcetrapib, a modest CETP inhibitor) has demonstrated no protective effect in patients with a recent acute coronary syndrome (ACS), even though there was evidence of improved cholesterol efflux activity [37-39]. Further studies are assessing other CETP inhibitors (evacetrapib and anacetrapib) in high vascular risk patients [40-42]. Accordingly, there is considerable interest in developing novel approaches to targeting HDL. One particular area of interest involves the concept of infusing delipidated forms of HDL, which may have the potential for rapid onset of action of lipid transporting and other biological activities of HDL.

\section{Infusing HDL containing apoA-I ${ }_{\text {Milano }}$}

$A p o A-I_{\text {Milano }}(A I M)$ is a genetic point mutation of apoA-I, resulting in an arginine to cysteine substitution at position 173. This mutation results in formation of AIM homodimers, with functional studies demonstrating favorable effects on cholesterol efflux, in addition to inflammatory and thrombotic mediators of atherosclerosis [43]. The variant was first identified in a cohort of northern Italian individuals, with evidence of low apoA-I and HDL-C levels, who appeared to be protected from cardiovascular disease. Escherichia coli based expression systems enabled generation of large quantities of recombinant AIM to produce reconstituted HDL particles in combination with phospholipid. These complexes were demonstrated to exert beneficial effects in animal models of balloon injury and atherosclerosis [44]. The combination of beneficial effects on endothelial function, aortic cholesterol content and platelet aggregation suggested potentially favorable effects in the setting of acute ischemic syndromes. Further studies in ex vivo and animal models of ischemia reperfusion demonstrating beneficial effects of AIM:phospholipid complexes on the extent of ischemic injury suggested potential additional benefits beyond direct effects on the artery wall [45-47].

A seminal proof-of-concept study demonstrated that administration of AIM:phospholipid (ETC216) exerted favorable effects on atherosclerotic plaque burden in patients with a recent acute coronary syndrome (ACS) [48]. Fifty-seven patients with an ACS in the preceding 2 weeks underwent intravascular ultrasonography within a coronary artery at baseline and following a treatment period in which they received intravenous infusions of saline or ETC-216 containing 15 or $45 \mathrm{mg} / \mathrm{kg}$ AIM weekly for 5 weeks. Significant reductions in percent atheroma volume by $1.06 \%(p=0.02)$ and total atheroma volume by $14.3 \mathrm{~mm}^{3}(p<0.001)$ were observed in ETC-216 treated patients, with no differences between the two active treatment groups. These changes were observed despite no discernible change in HDL-C levels at steady state. In fact, a greater degree of regression was observed in the lower dose group. Whether this reflects some degree of saturation of cholesterol mobilization, favoring efficacy at a lower dose, remains uncertain. Further analysis demonstrated the greatest degree of regression in the segments that contained the greatest amount of plaque at baseline and that regression appeared to associate with reverse remodeling of the artery wall $[48,49]$. All of these changes were associated with the observation that ETC-216 was well tolerated. The major challenge subsequent to this landmark study has been the ability to produce sufficiently large quantities in a form that can be employed 
in larger clinical trials. These limitations appear to have been overcome, and clinical development of $\mathrm{HDL}$ complexes containing AIM has recently continued.

\section{Infusing HDL containing wild-type apoA-I}

While the demonstration of rapid plaque regression with ETC-216 in humans provided an important proof-of-concept validation of potential benefits for HDL in humans, many in the field have been uncertain to what degree the specific protein composition influenced the results. While some investigators have reported that AIM possesses superior protective properties compared with wild-type apoA-I, others have not [50]. The effect of rHDL (reconstituted HDL) on Atherosclerosis-Safety and Efficacy (ERASE) study investigated the impact of infusing particles containing apoA-I (CSL-111) on coronary atherosclerosis [51]. One hundrd and eighty-three patients underwent serial intravascular ultrasonography to compare the effects of four weekly infusions of either saline or CSL-111 at a dose of 40 or $80 \mathrm{mg} / \mathrm{kg}$. The higher dose of CSL-111 was discontinued due to the early appearance of liver enzyme elevations that prohibited ongoing evaluation of that dose [51] While significant reductions in total atheroma volume by $3.4 \%(p<0.001)$ or $5.3 \mathrm{~mm}^{3}(p<0.001)$ were observed in the CSL-111-treated patients compared with baseline, these changes failed to meet statistical significance compared with placebo [51]. Additional measures of plaque reflecting plaque characterization and quantitative coronary angiography did demonstrate favorable benefits with CSL-111 compared with placebo [51]. Safety evaluation demonstrated that the lower dose of CSL-111 was associated with well-tolerated increases in liver enzymes. These findings suggest a potential benefit with HDL infusions containing apoA-I and support the concept that the administration of lipid-depleted HDL is beneficial in patients with coronary disease. Similar challenges with producing large quantities of agent have slowed down clinical development, although a reformulation (CSL-112) is now undergoing safety evaluation in a large study of patients following myocardial infarction (AEGIS-I).

\section{Infusing HDL containing sphingomyelin}

An alternative approach to developing reconstituted HDL particles is to modify its lipid components. The clinical development program for CER-001 has focused on the generation of negatively charged HDL complexes that contain wildtype apoA-I in combination predominantly with sphingomyelin. This is based on observations that sphingomyelin and negative charge may favorably influence the extent and duration of cholesterol mobilization [52]. Early studies in LDL receptor knockout mice demonstrated that administration of CER-001 enhanced reverse lipid transport and decreased the size of atherosclerotic plaque [53]. In the Can HDL Infusions Significantly Quicken Atherosclerosis Regression (CHI-SQUARE) study, 507 patients with acute coronary syndromes and angiographic coronary artery disease were randomized to treatment with 6 weekly infusions of placebo or CER-001 at a dose of 3, 6 or $12 \mathrm{mg} / \mathrm{kg}$ and underwent evaluation of the change in atheroma burden with serial coronary intravascular ultrasonography. Primary analysis of the change in total atheroma volume revealed reductions of $2.71 \mathrm{~mm}^{3}$ in the placebo group and by $3.13,1.50$ and $3.05 \mathrm{~mm}^{3}$ in the $3-12 \mathrm{mg} / \mathrm{kg}$ groups, respectively, failing to meet statistical significance [50]. A subsequent analysis performed by another core laboratory, which evaluated anatomically matched arterial segments, demonstrated reductions in total atheroma volume by $2.85 \mathrm{~mm}^{3}$ with placebo and by $4.76,3.34$ and $2.61 \mathrm{~mm}^{3}$ with increasing doses of CER-001 [50]. Per protocol analysis demonstrated a greater degree of regression of total atheroma volume at the $3 \mathrm{mg} / \mathrm{kg}$ dose, which was significantly greater than changes observed in the placebo group (-6.28 vs. $-3.63 \mathrm{~mm}^{3}$, $p=0.03$ ) [54]. Accordingly, a potential signal for regression at the lowest dose of CER-001 was observed. This is currently undergoing confirmation in a repeat imaging trial that will directly compare the effects of CER-001 $3 \mathrm{mg} / \mathrm{kg}$ vs. placebo.

\section{Autologous HDL infusions}

An alternative approach has emerged, which involves selective delipidation of a patient's own HDL, which subsequently undergoes autologous reinfusion. In a pilot study, 28 patients with an acute coronary syndrome and at least one nonobstructive native coronary artery were randomized to receive 7 weekly infusions of either delipidated HDL or plasma [55]. Serial intravascular ultrasonography demonstrated numerically greater regression in the HDL-infused patients, although this failed to meet statistical significance [55]. This approach is currently undergoing evaluation in a larger, more appropriately powered imaging study.

\section{Summary}

Several lines of evidence favor the protective properties of HDL, with evidence from imaging studies of potentially early changes in plaque burden in patients following an acute coronary syndrome. However, to date the efficacy of these agents has only been demonstrated on surrogate 
endpoints in imaging studies, and therefore the field is greatly in need of more definitive studies that investigate their effects on clinical outcomes. Each of these strategies requires ongoing validation before it can proceed to a large outcome trial, which will be required before these agents can be used in clinical practice.

\section{Conflict of interest}

The authors declare no conflict of interest.

\section{References}

1. Randomised trial of cholesterol lowering in 4444 patients with coronary heart disease: the Scandinavian Simvastatin Survival Study (4S). Lancet 1994; 344: 1383-9.

2. Prevention of cardiovascular events and death with pravastatin in patients with coronary heart disease and a broad range of initial cholesterol levels. The Long-Term Intervention with Pravastatin in Ischaemic Disease (LIPID) Study Group. N Engl J Med 1998; 339: 1349-57.

3. Sacks FM, Pfeffer MA, Moye LA, et al. The effect of pravastatin on coronary events after myocardial infarction in patients with average cholesterol levels. Cholesterol and Recurrent Events Trial investigators. N Engl J Med 1996; 335: 1001-9.

4. Shepherd J, Cobbe SM, Ford I, et al. Prevention of coronary heart disease with pravastatin in men with hypercholesterolemia. West of Scotland Coronary Prevention Study Group. N Engl I Med 1995; 333: 1301-7.

5. Barter P, Gotto AM, LaRosa JC, et al. HDL cholesterol, very low levels of $L D L$ cholesterol, and cardiovascular events. N Engl J Med 2007; 357: 1301-10.

6. Besler C, Luscher TF, Landmesser U. Molecular mechanisms of vascular effects of high-density lipoprotein: alterations in cardiovascular disease. EMBO Mol Med 2012; 4: 251-68.

7. Nicholls SJ, Dusting GJ, Cutri B, et al. Reconstituted high-density lipoproteins inhibit the acute pro-oxidant and proinflammatory vascular changes induced by a periarterial collar in normocholesterolemic rabbits. Circulation 2005; 111: 1543-50.

8. Gordon DJ, Probstfield JL, Garrison RJ, et al. High-density lipoprotein cholesterol and cardiovascular disease. Four prospective American studies. Circulation 1989; 79: 8-15.

9. Gordon DJ, Rifkind BM. High-density lipoprotein: the clinical implications of recent studies. N Engl J Med 1989; 321: 1311-6.

10. Gordon T, Castelli WP, Hjortland MC, Kannel WB, Dawber TR. High density lipoprotein as a protective factor against coronary heart disease. The Framingham Study. Am J Med 1977; 62: 707-14.

11. Emerging Risk Factors Collaboration, Di Angelantonio E, Sarwar N, Perry P, et al. Major lipids, apolipoproteins, and risk of vascular disease. JAMA 2009; 302: 1993-2000.

12. Badimon JJ, Badimon L, Fuster V. Regression of atherosclerotic lesions by high density lipoprotein plasma fraction in the cholesterol-fed rabbit. J Clin Invest 1990; 85: 1234-41.

13. Badimon JJ, Badimon L, Galvez A, Dische R, Fuster V. High density lipoprotein plasma fractions inhibit aortic fatty streaks in cholesterol-fed rabbits. Lab Invest 1989; 60: 455-61.
14. Nicholls SJ, Cutri B, Worthley SG, et al. Impact of shortterm administration of high-density lipoproteins and atorvastatin on atherosclerosis in rabbits. Arterioscler Thromb Vasc Biol 2005; 25: 2416-21.

15. Barter PJ, Nicholls S, Rye KA, Anantharamaiah GM, Navab M, Fogelman AM. Antiinflammatory properties of HDL. Circ Res 2004; 95: 764-72.

16. Angeloni E, Paneni F, Landmesser U, et al. Lack of protective role of HDL-C in patients with coronary artery disease undergoing elective coronary artery bypass grafting. Eur Heart J 2013; 34: 3557-62.

17. Kennedy DJ, Tang WH, Fan Y, et al. Diminished antioxidant activity of high-density lipoprotein-associated proteins in chronic kidney disease. J Am Heart Assoc 2013; 2: e000104.

18. McEneny J, Blair S, Woodside JV, Murray L, Boreham C, Young IS. High-density lipoprotein subfractions display proatherogenic properties in overweight and obese children. Pediatr Res 2013; 74: 279-83.

19. Park KH, Shin DG, Cho KH. Dysfunctional lipoproteins from young smokers exacerbate cellular senescence and atherogenesis with smaller particle size and severe oxidation and glycation. Toxicol Sci 2014; 140: 16-25.

20. Patel PJ, Khera AV, Wilensky RL, Rader DJ. Anti-oxidative and cholesterol efflux capacities of high-density lipoprotein are reduced in ischaemic cardiomyopathy. Eur J Heart Fail 2013; 15: 1215-9.

21. Otocka-Kmiecik A, Mikhailidis DP, Nicholls SJ, Davidson M, Rysz J, Banach M. Dysfunctional HDL: a novel important diagnostic and therapeutic target in cardiovascular disease? Prog Lipid Res 2012; 51: 314-24.

22. Dodani S, Dong L, Guirgis FW, Reddy ST. Carotid intima media thickness and low high-density lipoprotein (HDL) in South Asian immigrants: could dysfunctional HDL be the missing link? Arch Med Sci 2014; 10: 870-9.

23. Barylski M, Toth PP, Nikolic D, Banach M, Rizzo M, Montalto G. Emerging therapies for raising high-density lipoprotein cholesterol (HDL-C) and augmenting HDL particle functionality. Best Pract Res Clin Endocrinol Metab 2014; 28: 453-61.

24. Dragan S, Serban C, Banach M. Can we change the functionality of $\mathrm{HDL}$ cholesterol with nonpharmacological and pharmacological agents? Curr Med Chem 2014; 21 : 2927-46.

25. Toth PP, Barylski M, Nikolic D, Rizzo M, Montalto G, Banach $M$. Should low high-density lipoprotein cholesterol (HDL-C) be treated? Best Pract Res Clin Endocrinol Metab 2014; 28: 353-68.

26. Nicholls SJ, Tuzcu EM, Sipahi I, et al. Statins, high-density lipoprotein cholesterol, and regression of coronary atherosclerosis. JAMA 2007; 297: 499-508.

27. Athyros VG, Mikhailidis DP, Papageorgiou AA, et al. Effect of atorvastatin on high density lipoprotein cholesterol and its relationship with coronary events: a subgroup analysis of the GREek Atorvastatin and Coronary-heart-disease Evaluation (GREACE) Study. Curr Med Res Opin 2004; 20: 627-37.

28. Cui Y, Watson DJ, Girman CJ, et al. Effects of increasing high-density lipoprotein cholesterol and decreasing low-density lipoprotein cholesterol on the incidence of first acute coronary events (from the Air Force/Texas Coronary Atherosclerosis Prevention Study). Am J Cardiol 2009; 104: 829-34.

29. Lai HM, Aronow WS, Mercando AD, et al. The impact of statin therapy on long-term cardiovascular outcomes in an outpatient cardiology practice. Arch Med Sci 2012; 8: 53-6. 
30. Brown BG, Zhao XO, Chait A, et al. Simvastatin and niacin, antioxidant vitamins, or the combination for the prevention of coronary disease. N Engl J Med 2001; 345: 1583-92.

31. Canner PL, Berge KG, Wenger NK, et al. Fifteen year mortality in Coronary Drug Project patients: long-term benefit with niacin. J Am Coll Cardiol 1986; 8: 1245-55.

32. Taylor AJ, Villines TC, Stanek EJ, et al. Extended-release niacin or ezetimibe and carotid intima-media thickness N Engl J Med 2009; 361: 2113-22.

33. Barter P. CETP and atherosclerosis. Arterioscler Thromb Vasc Biol 2000; 20: 2029-31.

34. Barter PJ, Caulfield $M$, Eriksson $M$, et al. Effects of torcetrapib in patients at high risk for coronary events. N Engl J Med 2007; 357: 2109-22.

35. Bots ML, Visseren FL, Evans GW, et al. Torcetrapib and carotid intima-media thickness in mixed dyslipidaemia (RADIANCE 2 study): a randomised, double-blind trial. Lancet 2007; 370: 153-60.

36. Nissen SE, Tardif JC, Nicholls SJ, et al. Effect of torcetrapib on the progression of coronary atherosclerosis. N Engl J Med 2007; 356: 1304-16.

37. Schwartz GG, Olsson AG, Ballantyne CM, et al. Rationale and design of the dal-OUTCOMES trial: efficacy and safety of dalcetrapib in patients with recent acute coronary syndrome. Am Heart J 2009; 158: 896-901 e3.

38. Stein EA, Roth EM, Rhyne JM, Burgess T, Kallend $D$, Robinson JG. Safety and tolerability of dalcetrapib (RO4607381/JTT-705): results from a 48-week trial. Eur Heart J 2010; 31: 480-8.

39. Stein EA, Stroes ES, Steiner G, et al. Safety and tolerability of dalcetrapib. Am J Cardiol 2009; 104: 82-91.

40. Cannon CP, Shah S, Dansky HM, et al. Safety of anacetrapib in patients with or at high risk for coronary heart disease. N Engl J Med 2010; 363: 2406-15.

41. Cao G, Beyer TP, Zhang Y, et al. Evacetrapib is a novel, potent, and selective inhibitor of cholesteryl ester transfer protein that elevates HDL cholesterol without inducing aldosterone or increasing blood pressure. J Lipid Res 2011; 52: 2169-76.

42. Nicholls SJ, Brewer HB, Kastelein JJ, et al. Effects of the CETP inhibitor evacetrapib administered as monotherapy or in combination with statins on HDL and LDL cholesterol: a randomized controlled trial. JAMA 2011; 306: 2099-109.

43. Nicholls SJ, Uno K, Kataoka Y, Nissen SE. ETC-216 for coronary artery disease. Expert Opin Biol Ther 2011; 11: 387-94.

44. Ameli S, Hultgardh-Nilsson A, Cercek B, et al. Recombinant apolipoprotein A-I Milano reduces intimal thickening after balloon injury in hypercholesterolemic rabbits. Circulation 1994; 90: 1935-41.

45. Marchesi M, Booth EA, Rossoni G, et al. Apolipoprotein A-IMilano and 1-palmitoyl-2-oleoyl phosphatidylcholine complex (ETC-216) protects the in vivo rabbit heart from regional ischemia-reperfusion injury. J Pharmacol Exp Ther 2004; 311: 1023-31.

46. Speidl WS, Cimmino G, Ibanez B, et al. Recombinant apolipoprotein A-I Milano rapidly reverses aortic valve stenosis and decreases leaflet inflammation in an experimental rabbit model. Eur Heart J 2010; 31: 2049-57.

47. Marchesi M, Booth EA, Rossoni G, et al. Apolipoprotein A-IMilano/POPC complex attenuates post-ischemic ventricular dysfunction in the isolated rabbit heart. Atherosclerosis 2008; 197: 572-8.

48. Nissen SE, Tsunoda T, Tuzcu EM, et al. Effect of recombinant ApoA-I Milano on coronary atherosclerosis in patients with acute coronary syndromes: a randomized controlled trial. JAMA 2003; 290: 2292-300.

49. Nicholls SJ, Tuzcu EM, Sipahi I, et al. Relationship between atheroma regression and change in lumen size after infusion of apolipoprotein A-I Milano. J Am Coll Cardiol 2006; 47: 992-7.

50. Tardif JC, Ballantyne CM, Barter P, et al. Effects of the high-density lipoprotein mimetic agent CER-001 on coronary atherosclerosis in patients with acute coronary syndromes: a randomized trial. Eur Heart J 2014; 35: 3277-86.

51. Tardif JC, Grégoire J, L'Allier PL, et al. Effects of reconstituted high-density lipoprotein infusions on coronary atherosclerosis: a randomized controlled trial. JAMA 2007; 297: 1675-82.

52. Camont L, Lhomme M, Rached F, et al. Small, dense high-density lipoprotein-3 particles are enriched in negatively charged phospholipids: relevance to cellular cholesterol efflux, antioxidative, antithrombotic, anti-inflammatory, and antiapoptotic functionalities. Arterioscler Thromb Vasc Biol 2013; 33: 2715-23.

53. Tardy C, Goffinet M, Boubekeur N, et al. CER-001, a HDL-mimetic, stimulates the reverse lipid transport and atherosclerosis regression in high cholesterol diet-fed LDL-receptor deficient mice. Atherosclerosis 2014; 232: 110-8.

54. Weibel GL, Alexander ET, Joshi MR, et al. Wild-type ApoA-I and the Milano variant have similar abilities to stimulate cellular lipid mobilization and efflux. Arterioscler Thromb Vasc Biol 2007; 27: 2022-9.

55. Waksman R, Torguson R, Kent $K M$, et al. A first-inman, randomized, placebo-controlled study to evaluate the safety and feasibility of autologous delipidated high-density lipoprotein plasma infusions in patients with acute coronary syndrome. J Am Coll Cardiol 2010 55: 2727-35. 